\title{
Exploring the Policies Applied to Pharmaceutical Care Practice for Type 2 Diabetes over the Last Decade in European Community Pharmacies
}

\author{
Ângela Maria Vilaça Pereira de Araújo Pizarro ${ }^{a, b}$ Maria Rosário O. Martins ${ }^{a}$ b \\ Jorge Almeida Simões ${ }^{a, b}$ \\ ${ }^{a}$ Institute of Hygiene and Tropical Medicine, International Public Health and Biostatistics Unit, New University \\ of Lisbon, Lisbon, Portugal; ${ }^{b}$ Global Health and Tropical Medicine, Institute of Hygiene and Tropical Medicine, \\ International Public Health and Biostatistics Unit, New University of Lisbon, Lisbon, Portugal
}

\section{Keywords}

Type 2 diabetes mellitus · Community pharmacy services · Health policies $\cdot$ Regulatory policies

\begin{abstract}
In the last decade (2010-2020), more than half of European countries have improved their health policies within the primary care for type 2 diabetes mellitus. Community pharmacies have been and could continue to be essential actors in this evolution of fighting the disease by providing a set of pharmacotherapeutic follow-up services for the person with diabetes. These services, designated by the Pharmaceutical Group of the European Union as "diabetes management" and "glucose measurement", have aimed to optimize adherence to therapy and improve health outcomes. However, to follow the European guidelines of Good Pharmacy Practice, providing these services implies having a normative framework or a legal basis. Thus, this study sought to analyze the normative and regulatory framework on which community pharmacies in 28 European countries were based on providing this health care over the last decade.
\end{abstract}

(c) 2021 The Author(s). Published by S. Karger AG, Basel on behalf of NOVA National School of Public Health

\section{Explorando o enquadramento normativo para a prática dos cuidados farmacêuticos para diabetes tipo 2 nas farmácias comunitárias de 28 países europeus, na última década}

\section{Palavras Chave}

Diabetes mellitus tipo $2 \cdot$ Serviços de farmácia comunitária · Políticas de saúde · Regulamentação

\section{Resumo}

Na última década (2010-2020), mais da metade dos países europeus melhoraram as suas políticas de saúde no âmbito dos cuidados de saúde primários para a diabetes mellitus tipo 2. As farmácias comunitárias foram e poderão continuar a ser importantes intervenientes nesta evolução de combate à doença, através da disponibilização de um conjunto de serviços de acompanhamento farmacoterapêutico para a pessoa com diabetes. Serviços esses, designados, pelo Grupo Farmacêutico da União Europeia por "diabetes management" e "glucose measurement", visam otimizar a adesão à terapêutica e melhorar os resultados de saúde. No entanto, seguir as directrizes euro- karger@karger.com www.karger.com/pjp

Karger $\stackrel{\text { ' }}{=}$ BOPEN ACCESS (c) 2021 The Author(s). Published by S. Karger AG, Basel on behalf of NOVA National School of Public Health

This is an Open Access article licensed under the Creative Commons Attribution-NonCommercial-4.0 International License (CC BY-NC) (http://www.karger.com/Services/OpenAccessLicense), applicable to the online version of the article only. Usage and distribution for commercial purposes requires written permission.
Correspondence to:

Ângela Maria Vilaça Pereira de Araújo Pizarro, angela.pizarro@ihmt.unl.pt 
peias das Boas Práticas de Farmácia, para a realização destes serviços, implica dispor de um enquadramento normativo ou uma base jurídica. Assim, este estudo procurou analisar o arcabouço normativo e regulamentar, em que as farmácias comunitárias de 28 países europeus assentaram, para prestar estes cuidados de saúde, durante a última década.

(C) 2021 The Author(s).

Published by S. Karger AG, Basel

\section{Introduction}

One in eleven people worldwide has diabetes mellitus (DM) [1]. Most often referred to as diabetes, this is one of the most prevalent and uncontrolled non-communicable diseases globally [1]. Statistics predicted that, in 2040, there would be about 642 million adults with DM $[1,2]$. The same has happened in Europe in the last decade (2010-2020), i.e. 32.7 million new DM cases in adults, 12.8 million DM undiagnosed cases in adults, a prevalence of $6 \%$, and substantial expenses for treatment and prevention of its complications (e.g., health education for the general population through International Diabetes Federation recommendations for a healthy diet) [1] of about EUR 150 billion in total (EUR 4,600 per patient per year), were registered $[1,3]$. The most common (accounting for $90 \%$ of all cases), complex and heterogeneous pathological condition of diabetes is type 2 diabetes (T2DM) [1]. This disease is characterized by insulin resistance, compromising the functioning of the pancreas and causing the elevation of sugar levels (glucose) in the blood (hyperglycemia). Also, its most common diagnosis is based on the measurement results of blood glucose levels [1-4]. Still, some authors consider that one of these types of monitoring - the determination of the random/ occasional glucose - is insufficient to characterize diabetes [4]. Most people diagnosed with T2DM are old adults; still, it is increasingly detected in young people (i.e., children, adolescents, and young adults) due to increasing obesity, physical inactivity, and inadequate diet $[1,2]$. The most influential factors for the occurrence of T2DM (risk factors) are the lifestyle and behaviours commonly associated with urbanization [1]. In addition, the literature indicates that most cases of T2DM are prevented through a healthy diet and regular physical activity, helping to keep blood glucose levels under control [1]. Despite its high and growing global burden, diabetes is among the five pathologies whose hospitalization can be reduced or avoided through better prevention or management [1-6].
The World Health Organization (WHO) has appealed to international health systems to join multidisciplinary efforts to improve their annual strategic plans to fight diabetes. This call of action has mainly focused on hospitalization prevention, i.e., preventing diabetesrelated complications (e.g., non-therapy adherence) and ensuring the follow-up of patients living in the community through proximity's assistance provided by health professionals assistance, such as pharmacists in community pharmacies [7]. This role of pharmacists is based on providing health care that assesses the health status and the progression of the disease (i.e., clinical outcomes and medication history), ensuring the correct use of the medication and the maintenance of health results with a tendency towards normality (reference values, standard range, or reference range). Hence, it is called "Pharmaceutical Care" (PCNE, 2013) [8-10]. The provision of this care, in the context of T2DM, aims to identify the susceptible individuals (pre-diabetes, i.e., people with susceptibility to develop diabetes) or the patients (diabetes) through a blood glucose screening and the supervision of the medications' administration according to medical indication (posology) [8]. In most European countries, this care is provided through services, or rather two services called "glucose measurement” (i.e., measuring fasting and occasionally postprandial plasma glucose levels) and "diabetes management" (i.e., pharmaceutical consultation for people with a previous diagnosis of T2DM) (PGEU, 2019) [926]. Therefore, in addition to the physician and pharmacist, other health professionals should also be part of the health care team that treats T2DM patients. For example, nurses, for their essential role in diagnosis and proximity to the patient; pharmacists specializing in clinical pharmacy or pharmacology, as specialists in pharmacological therapy; and also nutritionists, psychologists, physiotherapists, podiatrists, among others, for the indication of non-pharmacological therapies (e.g., modifiable lifestyle habits such as diet, mental health, physical exercise, diabetic foot, respectively, and other factors that promote quality of life of patients) [27-31]. However, there is a lack of evidence on regulations and legal bases to provide pharmacy services under the guidelines for Good Pharmacy Practice in the last decade in Europe. So, it is crucial to evaluate the legal framework for these community pharmacy services' clinical and daily practice [33-51]. Therefore, our study sought to analyze whether, in European countries, there are guidelines/indications for community pharmacies to assist people with T2DM to assess wheth- 


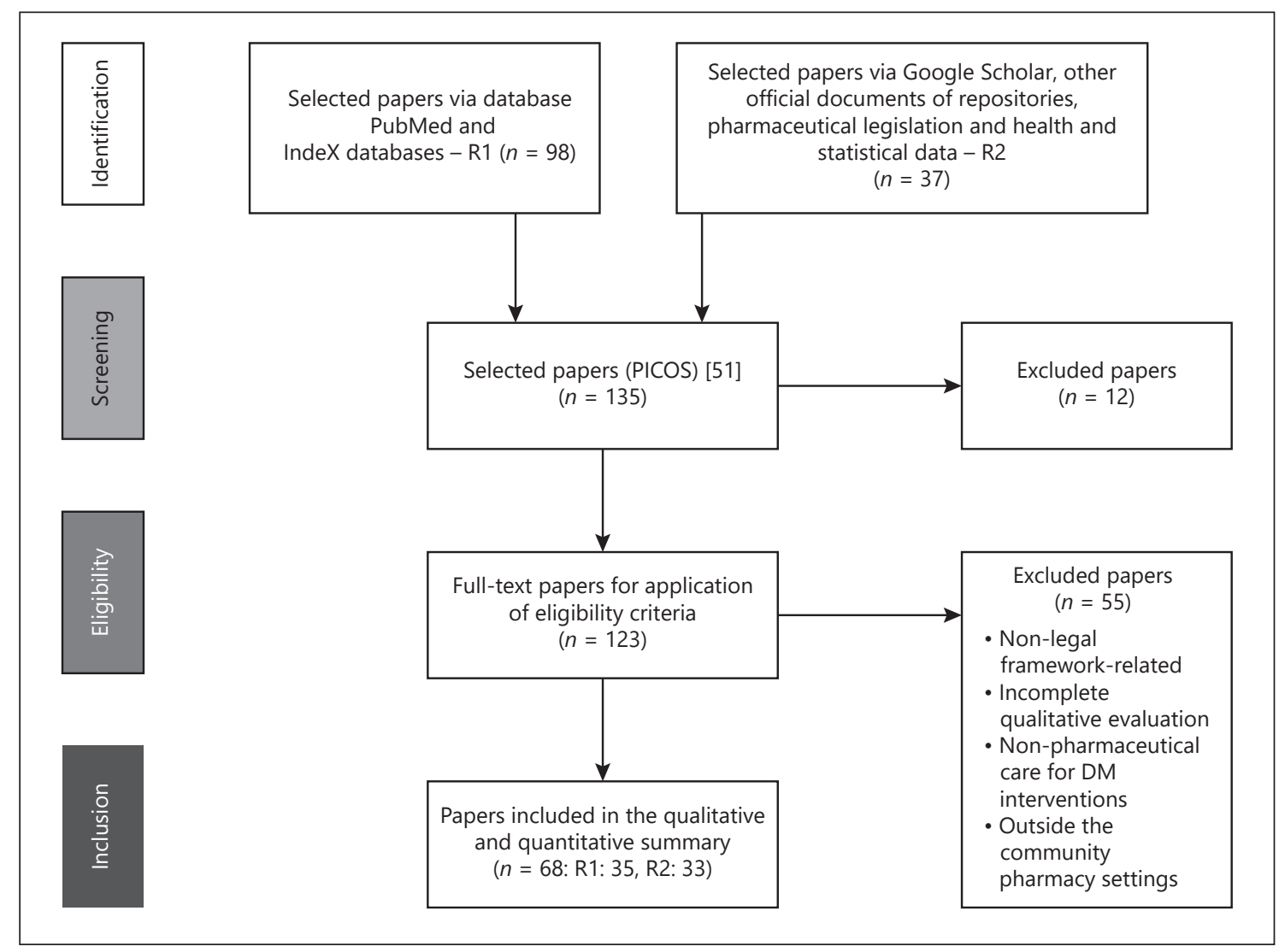

Fig. 1. Flow diagram: study selection and methodology used. PICOS, Participants, Interventions, Control, Outcomes, Study design; DM, diabetes mellitus.

er it is necessary to improve policies or implement better practices. The study included 28 countries, the UK and all EU countries, and was based on a literature review and a questionnaire.

\section{Methods}

The elaboration of the research question of our ecological study was based on the methodology "Participants, Interventions, Control, Results, Study design" (PICOS) [52, 53] and is as follows: What is the legal framework for community pharmacy services for type 2 diabetes' provision in European countries? To maximize the data collection, we made a dual research approach [54]. First, we started with a literature review (2010-2020) due to its advantages over other types of studies (i.e., precision, reliability, and systematization, a set of consistent and scientifically evident data and information). Then, we developed a questionnaire to be sent to the entities representing community pharmacies in each country to help us fill in some information that the authors might not have understood so well in the results of the literature review.

Pharmacy Services' Legal Framework for

T2DM in Europe, 2010-2020

\section{Literature Review}

The literature review followed two research paths: path R1 data collected from Google Scholar, PubMed, and IndeXed database; and path R2 - data collected from European and global health reports, among other health documents from international repositories (example, pharmaceutical legislation) and health statistics. R1 and R2 included the studies with the research question's descriptors in all possible designations for the term "pharmaceutical care OR pharmacy services" (in English) and without a defined time interval. On the other hand, we used the time interval 2010 to 2020 for the descriptors listed in online supplementary Table S0 (see www.karger.com/doi/10.1159/000519498 for all online suppl. material). Afterwards, we selected only the descriptors related to Europe and each EU-UK country (EU and the UK). Before this evaluation, the studies had to fulfil inclusion criteria. The inclusion criteria for R1 and R2 consisted of empirical studies related to all health policies and guidelines/indications for pharmaceutical care provision in community pharmacies related to diabetes care. They focused on pharmacy services' provision for patients with DM or T2DM with studies available and published in indexed scientific databases and full-text articles with a transparent and objective theme effectively related to the mentioned research question. The 
exclusion criteria included studies involving: (i) animals; (ii) people under 18; (iii) another type of diabetes (e.g., type 1 DM, gestational diabetes, diabetes insipidus); (iv) countries outside the EUUK; (v) inconclusive studies; studies without access to the full text; and studies related to the article's central theme with variations (for example, studies in a hospital OR hospital pharmacy environment, research in clinical trials, studies in health institutions other than community pharmacies). After this screening, we made the first selection and exclusion of studies. We validated the research question's elaboration criteria: participants/countries, guidelines/ protocols for providing community pharmacy services for T2DM (PS-T2DM), and health systems' intervention in terms of compliance, accordingly; and then. We analyzed the full texts which were more relevant using the same criteria to determine their inclusion eligibility in the review. Next, we tracked the data collected following the abovementioned research routes, $\mathrm{R} 1$ and $\mathrm{R} 2$, and excluded repeated studies. The third part of the systematic review was the study quality evaluation. Next, we tracked the data collected following the abovementioned research routes, R1 and R2, and excluded repeated studies. Thus, the third part of the systematic review was the study quality evaluation. The next step was to do a checklist of criteria which included an intervention variable (exposure) related to the legal framework for pharmaceutical care services for T2DM (i.e., regulation, policies, and guidelines, indications, norms, protocols), available in all EU-UK countries, a control variable. The second evaluation followed another checklist based on PRISMA statement ${ }^{\circledR}$ methodology - Preferred Reporting Items for Systematic Reviews and Meta-Analyses [55], which contained the study eligibility criteria. This analysis ended with a third assessment of the study quality, but only of R1. It consisted of an evaluation of resources through a bias assessment tool called ROBINS-I [56]. The study analysis was predominantly interpretative and qualitative with a comparative approach between the eligible countries (EU-UK) and the two related pharmacy services, whose designation was based on PGEU terminology [8] - blood glucose measurement (PS-T2DM-BGM) and diabetes management (PST2DM-DM). Also, the final set of studies chosen described the pharmaceutical services applicable to T2DM and related to DM, varying from country to country and, therefore, differing in terms of sociodemographic context - a criterion not considered as a variable. The flowchart (shown in Fig. 1) illustrates the dynamics of identifying studies and selecting them for analysis, according to the PRISMA statement ${ }^{\circledR}$ methodology. Lastly, we systematized this information in tables and figures presented in the main text and supplementary material.

\section{Questionnaire}

Subsequently, we developed an electronic questionnaire via Google ${ }^{\circledR}$, validated according to Boparai et al. [57], and pre-tested it (i.e., with the participation of three community pharmacists from three different EU-UK countries: Portugal, Sweden and United Kingdom). The questionnaire's content had the same purpose as the literature review, i.e., the analysis of the legal framework and its principles and objectives for the practice of PS-T2DM implemented until then (2020) in each EU-UK country. We sent the questionnaire to the official entities representing the community pharmacy sector in each country and received their responses within four weeks. The collected data were analyzed using descriptive statistics, and we compared the mean responses of the group using $t$-tests [57-60]. Finally, we systematized this information in a table.

\section{Results}

The sources of the study results were:

1. The literature review of 35 scientific articles that we collected from scientific databases (R1);

2. The literature review of 33 documents found on the official national and European websites (i.e., legislation, guidelines, regulations, and recommendations), in English (R2) (shown in Fig. 1, Table 1, and online suppl. Table S1);

3. The electronic questionnaire (shown in online suppl. Table S2).

\section{Literature Review}

The literature review took the two paths of research, i.e., R1 and R2. First, we characterized the R1's studies with the ROBINS-I tool [56] (shown in online suppl. Table S1 and online suppl. Fig. S1). Then, we explored 31 of these studies (shown in Table 1), according to the preestablished selection criteria (shown in Tables 2 and 3). Thus, we observed that 20 of these studies had relevant data to answer our research question; and the most mentioned theme in the studies was "pharmaceutical care" (17 studies).

\section{Questionnaire}

Eighteen countries (of the 28 European countries) replied to the questionnaire, and their answers are shown in online supplementary Table S2.

\section{International Comparison}

We collected information about two main themes: the health policies developed and implemented to reduce the burden of DM - obtained in 26 countries (shown in Table 2 ) -, and the legal framework for the practice of pharmacy services for T2DM (PS-T2DM) - gotten in 20 of those countries (shown in Table 3 ). Thus, we could observe that European countries have established plans to reduce the diabetes burden and adopted evidence-based objectives and principles to provide some pharmacy services in community pharmacies (PS-T2DM) under international rules, i.e., the Good Pharmacy Practices, the Clinical Guidelines for Chronic Conditions in the EU, the WHO Mixed Guidelines International Pharmaceutical Federation [9-26, 36], and the General Data Protection Regulation [37]. Then, we profiled each European country according to a set of characteristics of a target country (i.e., a country that is an example of reasonable pharmaceutical practice in diabetes [7]), and we compared countries between them. The points of comparison included the 
Table 1. Characteristics of included studies using the search way R1

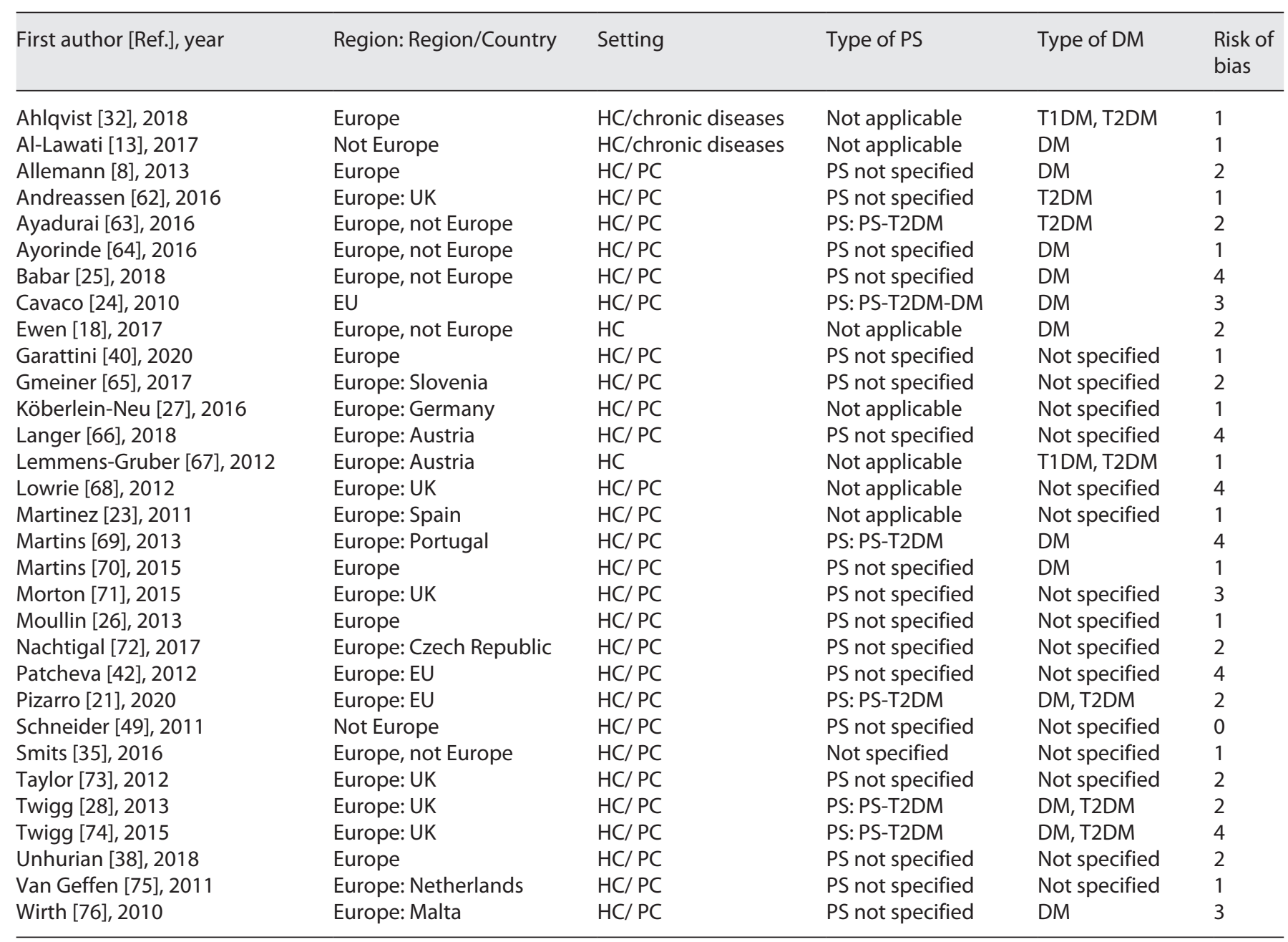

D, domain. Risk of bias assessment - 0: no information; 1: low; 2: moderate; 3: serious; 4: critical. T1DM, type 1 diabetes mellitus. T2DM, type 2 diabetes mellitus; DM, diabetes mellitus; PS-T2DM, Pharmacy services for type 2 diabetes mellitus; HC, health care; PC, pharmaceutical care; PS, community pharmacy services.

existence of operational policies/strategies/action plans for DM; national diabetes registry; guidelines/protocols/ standards for diabetes included in action plans; and procedures regarding the patients' referral from primary to advanced care (secondary and tertiary care) (shown in Table 2). Then, we made two more comparative analyses as follows.

Health Policies for DM Prevention and Management The first analysis was based on the perception of health policies for diabetes and their regulations (shown in Table 2, Fig. 2, and Table 3 of the supplementary material). As a result, we concluded that the UK, Slovenia,
Slovakia, Finland, and Cyprus showed a regulatory framework for preventing and managing diabetes identical to the target country. In detail, we observed that: (i) 25 countries implemented action plans to minimize the burden of DM, and in 13 of them there was a national registry of DM cases; (ii) 20 countries had established guidelines, protocols, and standards for DM management, 14 of them implemented these rules thoroughly; and (iii) 19 countries followed guidelines and protocols for a medical referral from primary to a higher level of care, 13 of them implemented these rules entirely. 
Table 2. Country profiles: legal framework (policies and guidelines) for diabetes mellitus' prevention and management in EU-UK

\begin{tabular}{|c|c|c|c|c|}
\hline & \multicolumn{2}{|l|}{ 1. Policies } & \multicolumn{2}{|l|}{ 2. Guidelines } \\
\hline Belgium & yes & no & Available and fully implemented & Available and fully implemented \\
\hline Bulgaria & yes & no & Available and fully implemented & Available and fully implemented \\
\hline C. Republic & yes & no & Available and fully implemented & Available and fully implemented \\
\hline Croatia & yes & yes & NDA & NDA \\
\hline Cyprus & yes & yes & Available and fully implemented & Available and fully implemented \\
\hline Denmark & yes & yes & Available and partially implemented & Available and partially implemented \\
\hline Greece & yes & no & NDA & NDA \\
\hline Hungary & yes & no & NDA & NDA \\
\hline Ireland & yes & no & Available and fully implemented & Available and partially implemented \\
\hline Italy & yes & no & Available and partially implemented & Available and fully implemented \\
\hline Latvia & yes & yes & NDA & NDA \\
\hline Lithuania & yes & no & Available and fully implemented & Available and fully Implemented \\
\hline Luxembourg & NDA & NDA & NDA & NDA \\
\hline Malta & yes & yes & NDA & Available and partially Implemented \\
\hline Netherlands & yes & no & Available and fully Implemented & NDA \\
\hline Poland & yes & no & NDA & NDA \\
\hline Portugal & yes & yes & Available and partially implemented & Available and partially implemented \\
\hline Romania & yes & yes & Available and partially implemented & Available and fully implemented \\
\hline
\end{tabular}

EU-UK, European Union countries $(N=27)$ and the United Kingdom; NDA, no data available (country reported "do not know" OR "Not available," OR available data was not found according with our study criteria, OR country did not answer), [a] Information based on questionnaire; Respondents of questionnaire: Belgian Pharmaceutical Association (Belgium), Bulgarian Pharmaceutical Union (Bulgaria), Croatian Chamber of Pharmacists (Croatia), The Association of Danish Pharmacies (Denmark), Estonian Pharmacies Association(Estonia), Association of Finnish Pharmacies (Finland), Federal Union of German Pharmacists Association (Germany), Panhellenic Pharmaceutical Association (Greece), Hungarian Chamber of Pharmacists (Hungary), Irish Pharmacy Union (Ireland), Latvian Pharmacy Owners Association (Latvia), Malta Chamber of Pharmacists (Malta), Portuguese Royal Pharmaceutical Society (a Community Pharmacist working in a Portuguese Community Pharmacy) (Portugal), Slovak Chamber of Pharmacists (Slovakia), General Council of Spanish Pharmacists (Spain), Swedish Pharmacy Association (a Community Pharmacist) (Sweden), Royal Dutch Pharmaceutical Association (The Netherlands), General Pharmaceutical Council (a Community Pharmacist) (UK, Cambridge).

Legal Framework for PS-T2DM Provision in EU-UK Community Pharmacies

Then, we refined our research, analyzing the legal framework of the practice of PS-T2DM: we combined the questionnaire's answers with the literature review results obtained in $\mathrm{R} 1$ and $\mathrm{R} 2$ research paths (shown into each country's profile) and compared them with the target country (Fig. 3, Table 3, and online suppl. Tables S3, S4, S5, S6 and S7). As a result, we obtained coherent data from 20 countries. Even if 18 countries had referred to 


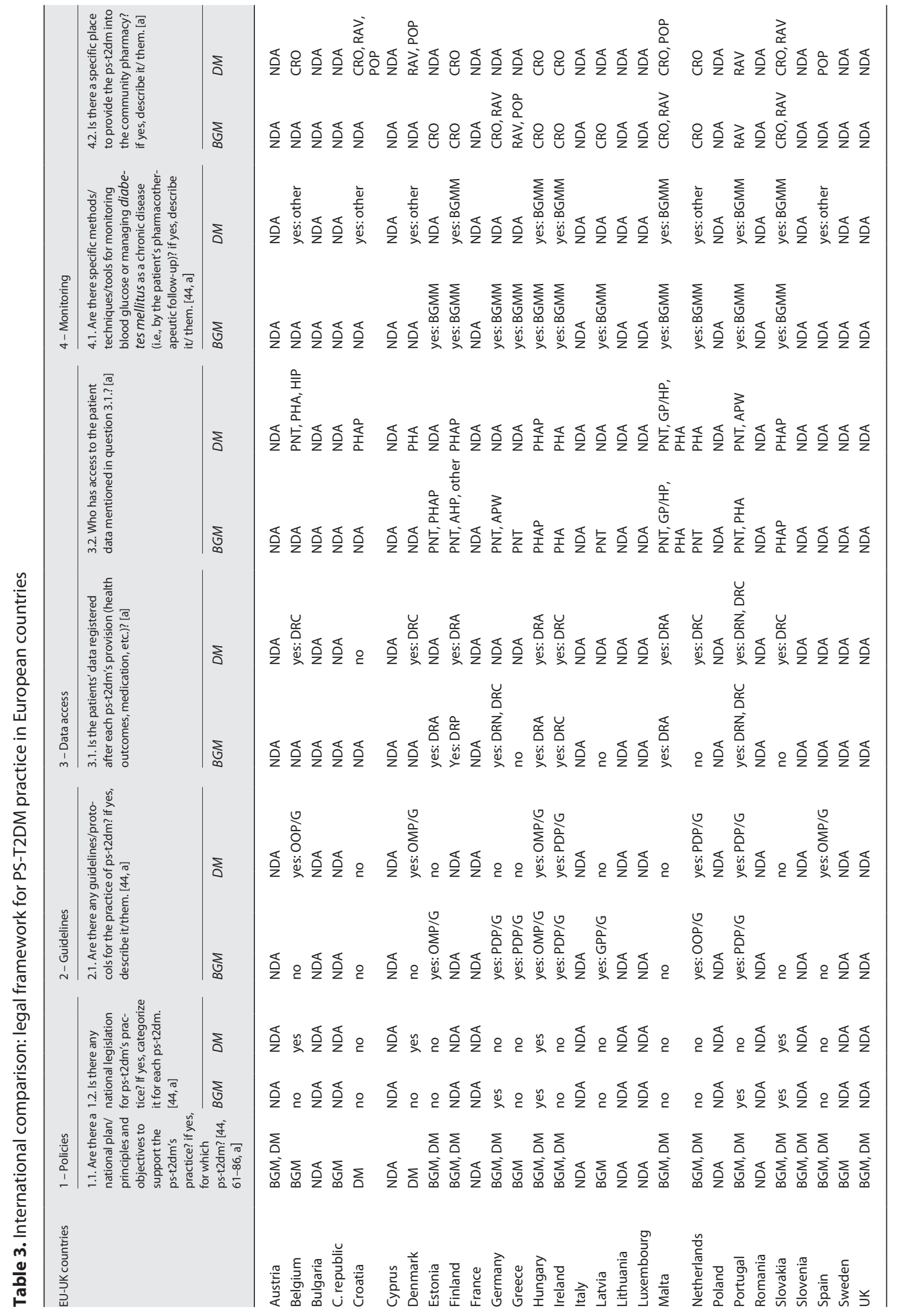




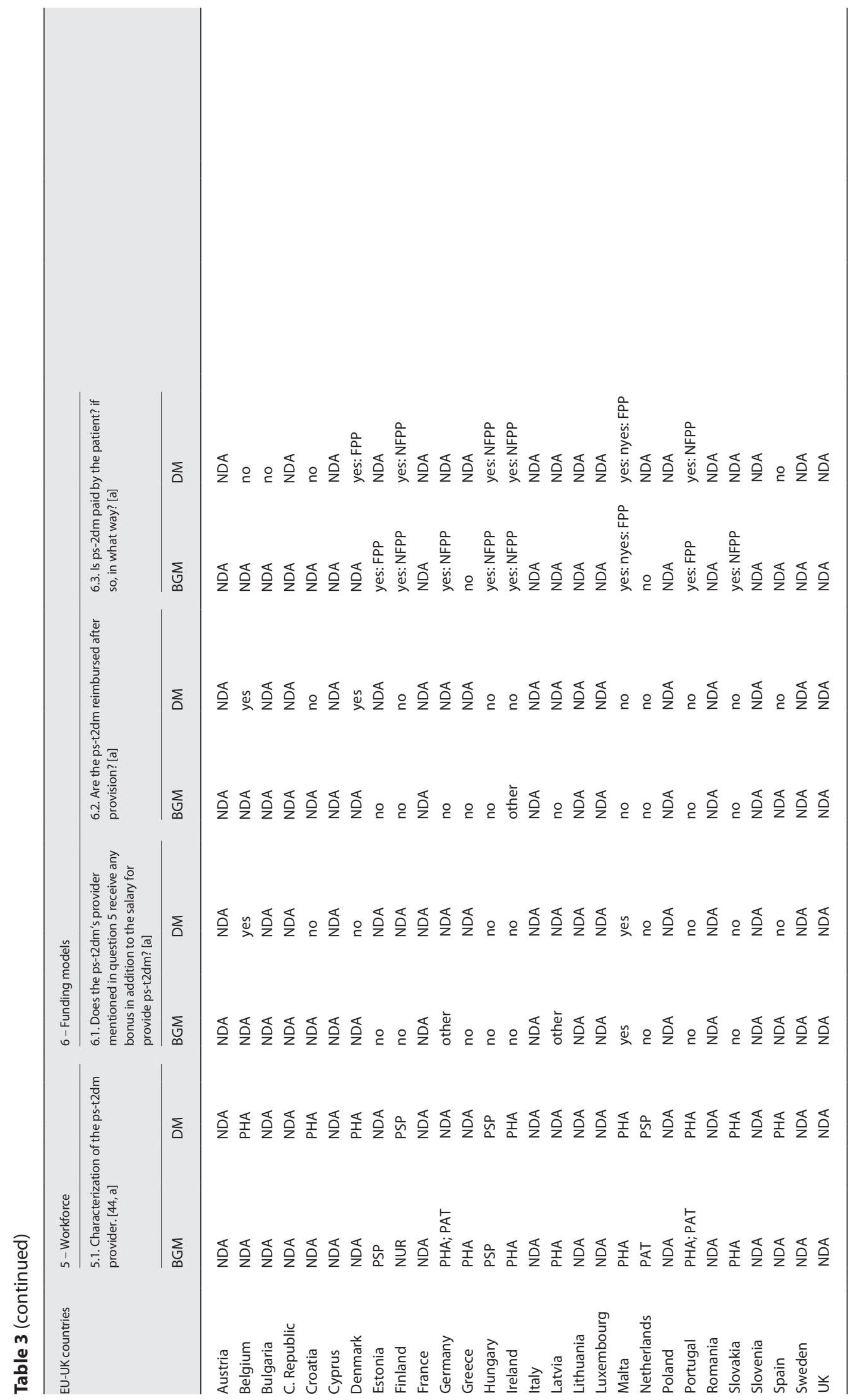

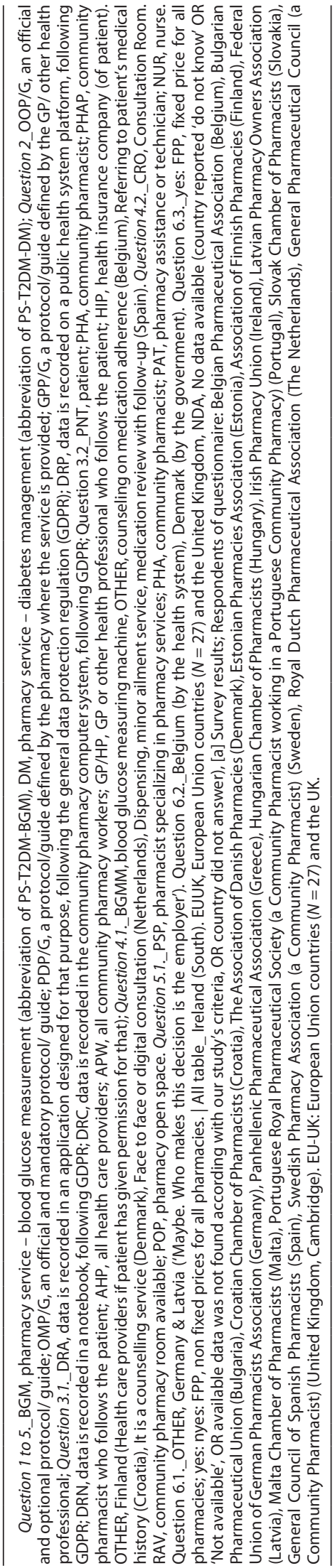




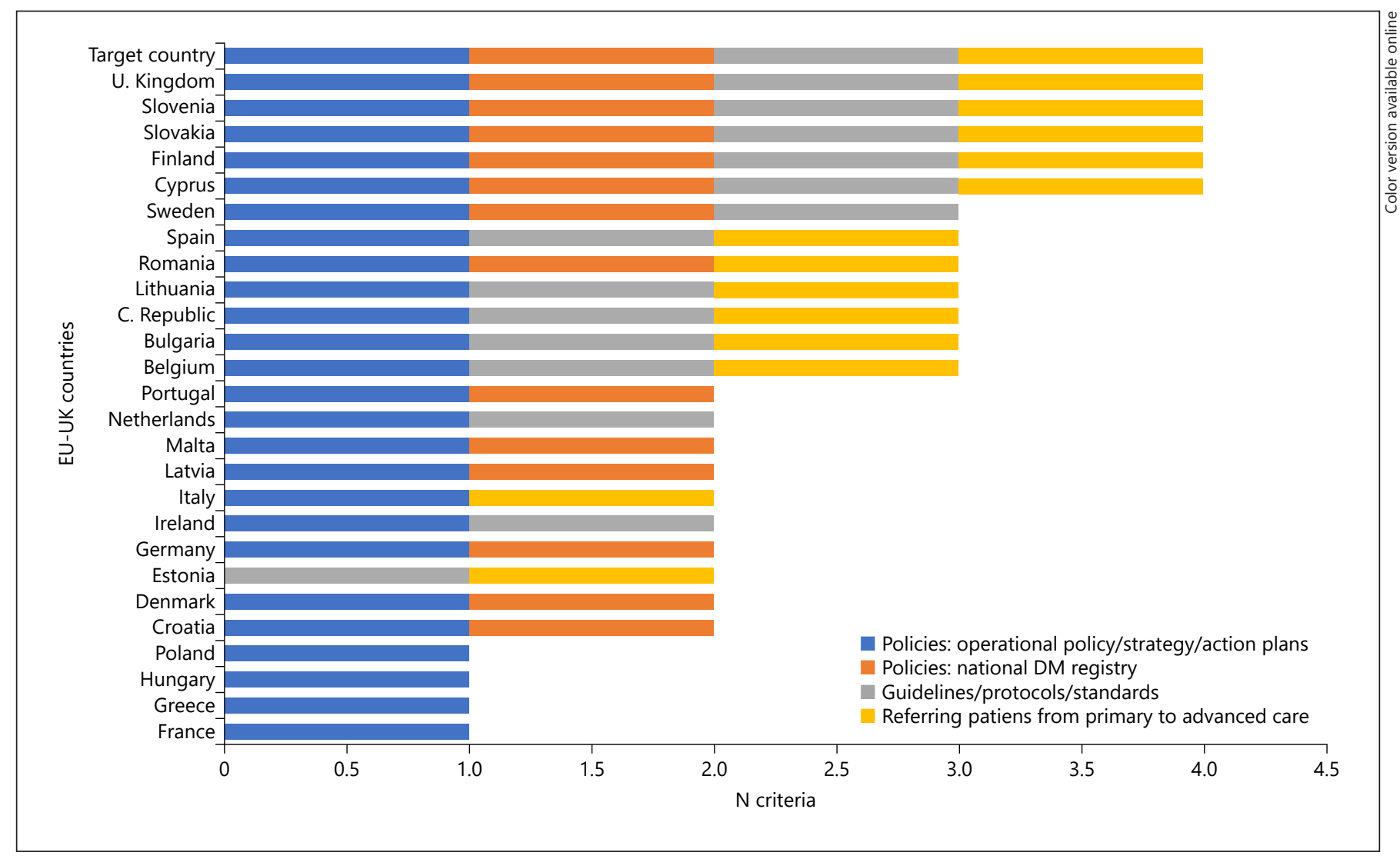

Fig. 2. Country profiles: legal framework (policies and guidelines) for diabetes mellitus' prevention and management in European countries. Policies corresponding to Question 1.1. of Table 2; DM National Registration corresponding to Question 1.2. of Table 2;
Guidelines corresponding to Question 2.1. of Table 2; Referring corresponding to Question 2.2. of Table 2. Although included in the analysis, we excluded 2 countries that had no results: Austria and Luxembourg. Goal Country: "target country." implementing the "glucose measurement" service (PST2DM-BGM), only Hungary and Portugal had close results to the target country (shown in online suppl. Fig. S2 and Table S5). We also observed that 16 of those countries implemented "diabetes management" service (PS-T2DMDM), but only Belgium and Denmark showed the target country's closest profile (shown in online suppl. Fig. S3 and Table S6).

Table 3 shows the country's profile characterization according to the following points:

Guidelines and Protocols to Guide the PS-T2DM Provision in EU-UK. Hungary, Ireland, Portugal, and The Netherlands reported following established guidelines and protocols for both PS-T2DM's provision, and Hungary and Slovenia reported having available legislation to support that.

Registration and Access to Patient Health Data during the Provision of PS-T2DM. Some countries reported that patient health data was collected during the provision of the pharmacy service (e.g., the values of blood pressure, total cholesterol, blood glucose, or the name of a new prescription drug). They also detailed that this data is recorded using information technologies according to the GDPR $[37,78]$ : Belgium, Denmark, Germany, Ireland, The Netherlands, Portugal, and Slovakia made this data registration on a computer (Note: Germany and Portugal also reported to make the data registration in a notebook); Estonia, Finland, Hungary, and Malta recorded data in a digital platform/ application designed for that purpose; and Finland recorded data in the public health system platform. Furthermore, in The Netherlands, the "diabetes management" service could be face-to-face consultation or a digital consultation; and in Belgium this service could be a provided by a reference pharmacist. Besides, in seven countries, the pharmacist was the only health professional or pharmacy worker who can access the PS-T2DM-DM 


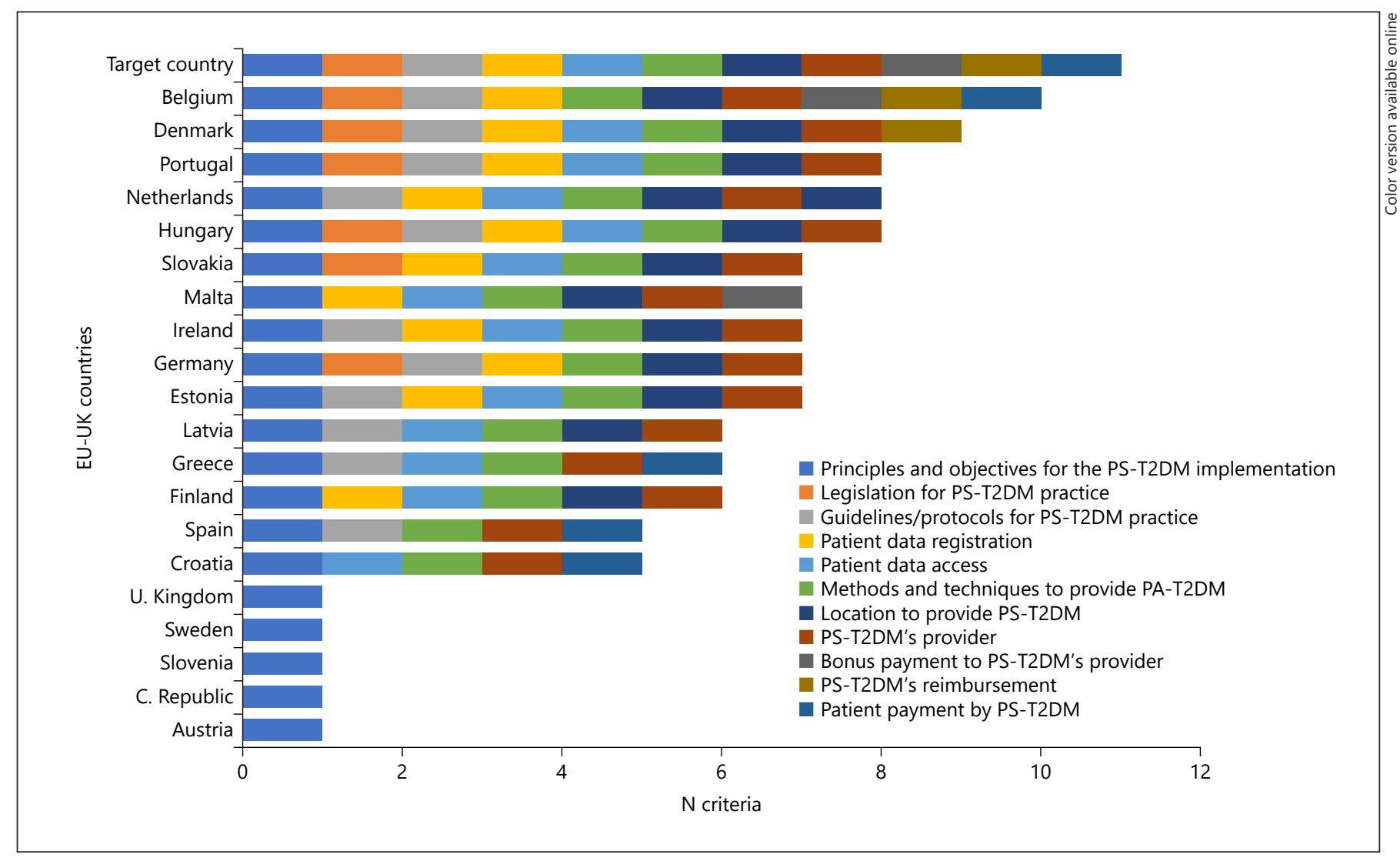

Fig. 3. International comparison: legal framework for PS-T2DM practice in European countries. The criteria were as follows: Policies corresponding to Question 1.1. of Table 3; Legislation corresponding to Question 1.2.; Guidelines corresponding to Question 2.1; Patient Data Registration corresponding to Question 3.1.; Patient Data Access corresponding to Question 3.2.; Methods corresponding to Question 4.1; Local of the PS-T2DM's Provision

data. In Belgium, Germany, The Netherlands, and Portugal, patients also.

Glucose Measurement in Both PS-T2DM: Materials, Methods and Techniques. Eleven countries reported using glucometers, to monitoring the glycaemia levels: eleven countries reported it for the for PS-T2DM-BGM provision and six countries for PS-T2DM-DM. We also observed: some different methods to provide PS-T2DM between countries, whose common denominator was always a counselling service, such as detailed by Belgium, Croatia, Denmark, The Netherlands, and Spain; some different places where the service occurred, such as a "consultation room" at the pharmacy to provide both PS-T2DM was mentioned by eight countries, to provide PS-T2DM-BGM reported by Estonia and Latvia and to provide PS-T2DM-DM reported by Belgium corresponding to Question 4.2.; PS-T2DM's PROVIDER corresponding to Question 5.; Bonus corresponding to Question 6.1.; PS-T2DM's Reimbursement corresponding to Question 6.2.; Patient corresponding to Question 6.3. Eight countries were excluded from this figure because they did not report or did not find valid information according to our criteria - Bulgaria, Cyprus, France, Italy, Lithuania, Luxembourg, Poland, and Romania. (i.e., characterized as counselling medication adherence service).

PS-T2DM Providers. Pharmacists have been the most common Pharmaceutical Care providers, as observed in 15 countries. In some cases, these pharmacist have to be pharmacy services' specialists (Estonia, Finland, Hungary, and The Netherlands), mainly to provide PS-T2DMDM. In other cases, the PS-T2DM-BGM (blood glucose measurement with glucometer) could be provided by nurses (Finland) and pharmacy technicians (Germany and Portugal), even though they were delegated by the pharmacist.

Funding Models for PS-T2DM's Provision. The provider is paid through a salary bonus in four countries: Belgium, Germany, Latvia, and Malta. On the other hand, the PS-T2DM-DM service directly costs the patient in five 


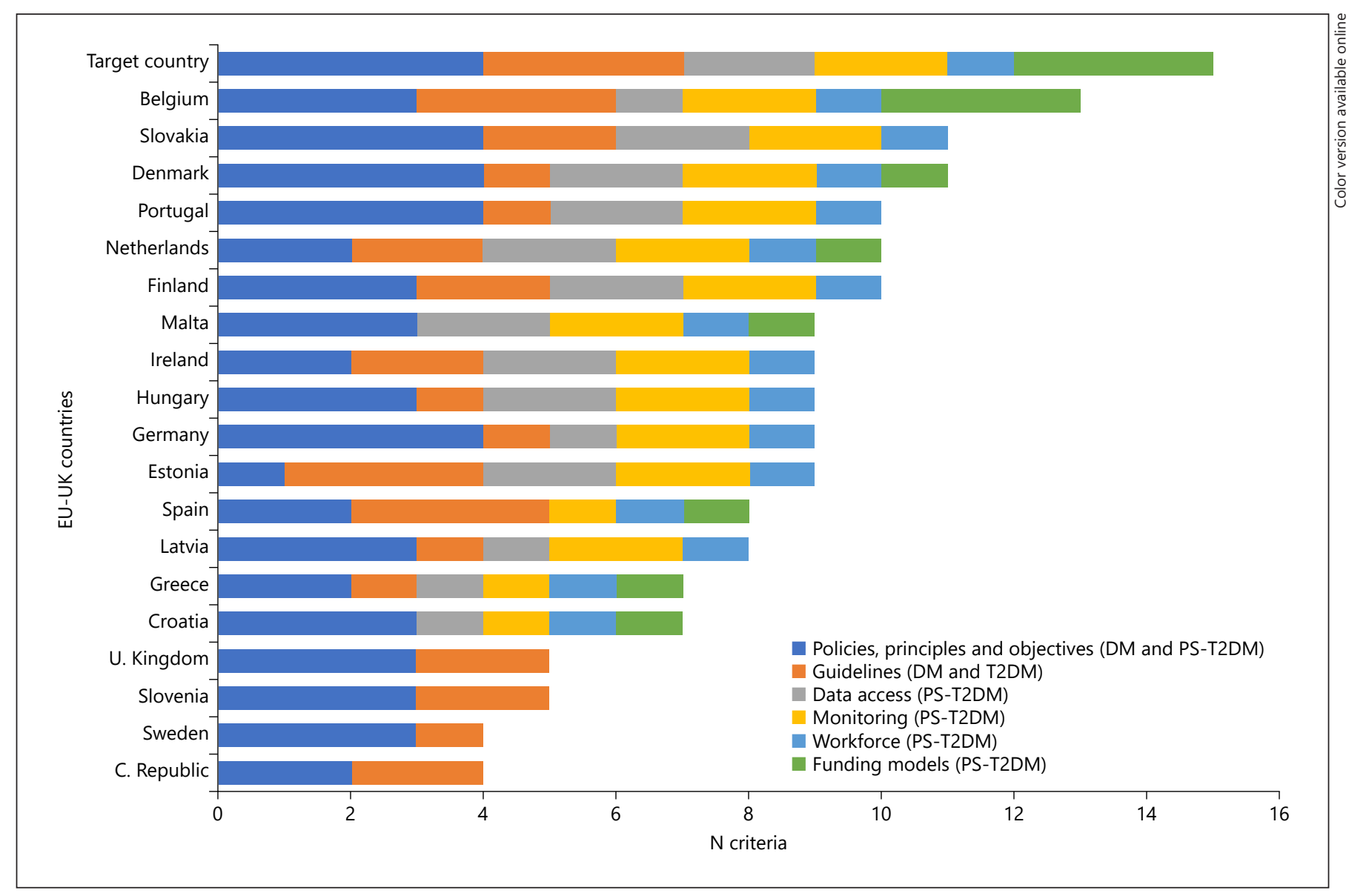

Fig. 4. International comparison: legal framework for diabetes mellitus' prevention and management and PST2DM practice in European countries.

countries (Belgium, Croatia, Greece, Spain and Portugal). Still, only Belgium has stated that it has a reimbursement policy for both PS -T2DM.

\section{Discussion}

Over the past decade, some European health systems have recognized the value of pharmaceutical care to improve the T2DM patient's health and quality of life, including this type of care patient-centred in their primary health care programs $[8,36,79,80]$.

Twenty-six of these countries evidenced national plans for the prevention of diabetes. Also, five of these countries were shown to be an example to follow because of their robust regulatory, normative, legal, political, and organizational structure related to the PS-T2DM provision: UK, Slovenia, Slovakia, Finland, and Cyprus (shown in Table
3 and Figure 4). However, this does not rule out the hypothesis that countries excluded from these results have appropriate DM regulations or PS-T2DM.

On the one hand, we classified 19 countries as candidates to be a target country, and we concluded that the most relevant DM legal framework was adopted in the UK, Slovenia, Slovakia, Finland, and Cyprus for the first category ("The legal framework for DM prevention and management"). Moreover, Belgium was the closest country to be a candidate pattern of a legal framework for the second category ("the legal framework for DM pharmacy services' provision"). On the other hand, when we gathered the results of these two categories, we could observe that, in general terms, the countries or group of countries with the most corresponding criteria to target country were Belgium, Slovakia and Denmark, and Finland, Portugal and The Netherlands (shown in Fig. 5). Also, in a particular approach, the countries that matched better 


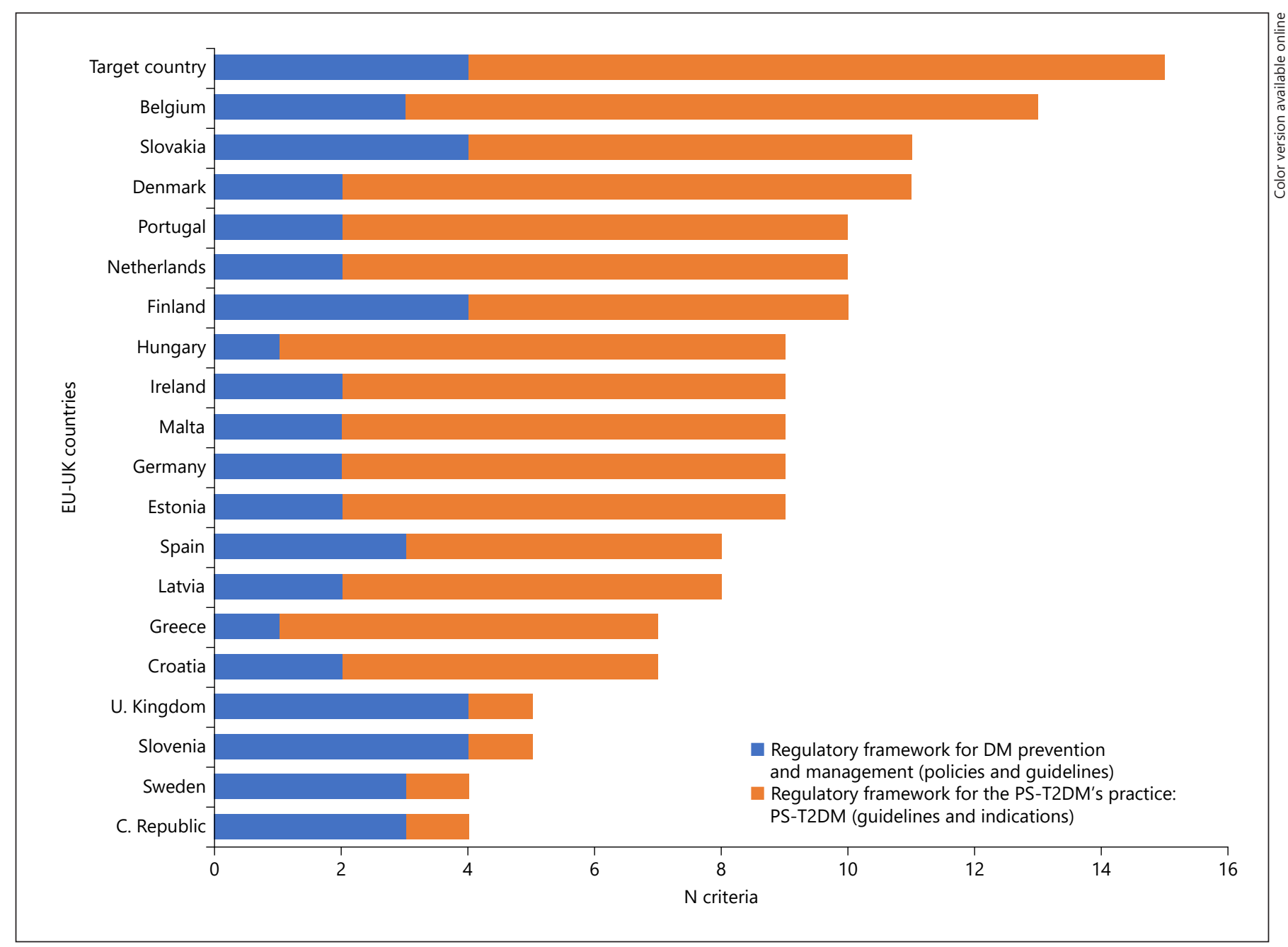

Fig. 5. International comparison: Legal framework for type 2 diabetes mellitus' prevention and management and PS-T2DM's practice in EU-UK.

the target country in the different criteria of both categories were: (a) Denmark, Germany, Portugal, and Slovakia - for the implementation of policies for the diabetes eradication, including T2DM; Belgium, Estonia, and Spain for the performance of the guidelines, protocols and indications for the diabetes care in community, including the T2DM; Estonia, Slovakia, Finland, The Netherlands, Ireland, Denmark, Portugal, Hungary, and Malta - for the patients' health data access compliance with rules; Estonia, Slovakia, Finland, The Netherlands, Ireland, Denmark, Portugal, Hungary, Malta, Belgium, and Germany - for the outcomes "monitoring" according to good pharmacy practices; Estonia, Slovakia, Finland, Netherlands, Ireland, Denmark, Portugal, Hungary, Malta, Belgium, Germany, Latvia, Greece, Croatia, and Spain - for the multidisciplinary patient follow-up and counselling; and Belgium - for the sustainability of the PS-T2DM provision system and process.

Besides, two different themes attracted our attention: the use of new information technologies (IT) for data sharing in community pharmacies and the remuneration of the pharmaceutical care service's - because only around half of the countries reported having the habit of electronically recording data and this lack of IT use could have avoided more rigorous monitoring of health outcomes, i.e. follow-up over the time of a range of glycemic values [87]. In addition, in some countries, access to this data was allowed for interested parties other than health professionals or patients, such as health insurers. This issue is ethically questionable in 
terms of confidentiality and misuse of data $[37,78]$. For the second theme, we found that the PS-T2DM provider was paid as a salary bonus in some European countries, however, this was not the case in most of them. To prove the importance of these topics, it will be essential to estimate how to reasonably pay the provider, and not just demonstrate the benefits of the services or prove that it is an economic activity. Furthermore, in line with the cost-effectiveness of providing PS-T2DM, we also find that "automatic" counselling (i.e., without the intervention of community pharmacists, as they only dispense prescription drugs) is less attractive to pharmacists because it would neglect their knowledge and skills and the patients lost information about their treatment, and the health system would waste the investment in qualified human resources.

Therefore, to help European healthcare systems fight T2DM and DM, we made three recommendations, which are presented below. The first one was the need to legally establish pharmacies as a primary point of contact between patients and the health system and the pharmacist as the responsible person for monitoring health outcomes and adherence to therapy. Second, another challenge is related to equip community pharmacies with information technology devices and other tools to help achieve and improve the performance of the first challenge, according to the GDPR $[37,78]$. And the final challenge, imperative for WHO and already achieved in very few European countries, is to encourage the long-term relationship between the health care team's professionals (and their institutions) who follow the T2DM patient's treatment, giving them conditions for sharing data and discussing health outcomes to refer the patient to a higher health care level.

However, for all these proposals be achieved, it is necessary to consider so the health financing models available to each country as the identity of each stakeholder involved. For example, in some countries, such as Portugal, where a single National Health Service (a public service) is involved, this cost-effective decision is more easily debatable than in a multiple payer system that integrates, for example, health insurance companies (e.g., Switzerland [81]). This set of common interests must have an essential pillar, that is, a regulatory, institutional, and relationship framework between health professionals who manage the patient core outcome set created within the scope of the health system to answer the health needs of each country, that is, it must have the aforementioned legal framework [82].

Pharmacy Services' Legal Framework for T2DM in Europe, 2010-2020

\section{Limitations}

The heterogeneity of some studies' information and the data loss (either in electronic search engines or in questionnaires) could be the biggest limitation. A specific reason could be the complex search for a single terminology or a uniform name for the term "pharmaceutical care" and the term "pharmacy service." In addition, as an ecological study, we subjected the study to some bias. The main risk of bias was not controlling all confounding factors, deciding between two studies with different results, qualifying all research sources, and dissociating T2DM from other types of diabetes in the same document. This last obstacle was due to the generalization of the concept of diabetes in the literature when the study was related, for example, to type 2 , type 1 , gestational diabetes, or diabetes insipidus. Regarding the questionnaire, the response rate in the countries was $64 \%(N=18)$. This result may represent a risk of non-response bias. Furthermore, the lack of incentive for research or response and a nonindividual approach (i.e., to a representative or spokesperson for the reporting entity) could cause it. In addition, all questions in the questionnaire focused on a standard model of PS-T2DM and not a specific model for the community pharmacies' setting of each country; and some of the responses to the questionnaire were labelled "No data available," "I do not know" OR "Not available." These two facts may have compromised the precision of the country comparison results regarding the "target country" or EU-UK average expectations.

\section{Conclusion}

In the last decade, more than half of European countries have recognized the pharmaceutical care provided by pharmacists at community pharmacies as an indispensable tool to help health systems reduce the burden of diabetes. The "diabetes management" and the "glucose measurement" services were implemented for this purpose, but there is little evidence about their practice's legal framework. To respond to this gap, we observed that each European country adopted its strategies to implement pharmacy services. Some countries stood out for having a robust and well-established normative and regulatory framework, i.e. Belgium, Denmark, Portugal, Slovakia, and The Netherlands. However, even in these countries, there was less evidence about: the principles, objectives, methodologies, and guidelines for the execution of services; the multidisciplinary nature of the health team that treats/follows-up patients with T2DM; the cost-effective-

Port J Public Health 2021;39:103-118 
ness of these services; and the use of information technologies for recording and sharing health data. This information will be essential if the main objective of European community pharmacies is to plan, validate, maintain, or integrate the primary care network in the distinguished rule to monitor chronic and acute patients living in the community and consequently help improve the sustainability of the health systems.

\section{Acknowledgement}

Thanks to the contribution of Belgium Order of Pharmacists (Belgium), Bulgarian Pharmaceutical Union (Bulgaria), Croatian Pharmaceutical Society (Croatia), The Association of Danish Pharmacies (Denmark), Estonian Pharmacies Association (Estonia), Association of Finnish Pharmacies (Finland), Federal Union of German Pharmacists Association (Germany), Panhellenic Pharmaceutical Association (Greece), Irish Pharmacy Union (South Ireland), Latvian Pharmacy Owners Association (Latvia), Malta Chamber of Pharmacists (Malta), Slovak Chamber of Pharmacists (Slovak Republic), General Council of Spanish Pharmacists (Spain), Royal Dutch Pharmaceutical Association (Netherlands), Inês Pinto (Portuguese Order of Pharmacists, Portugal), Andreia Franco Silva (General Pharmaceutical Council, United Kingdom), Professor Joao Rui Pita (Faculty of Pharmacy of the
University of Coimbra, Portugal), International Federation of Pharmacists of the European Union Group (Netherlands), Sophie Gerkens (Belgium), Bruna Vinci (Italy), Mircha Poldrugovac (Slovenia), Michael van den Berg (OECD, Netherlands), Antonio Grasso (PGEU), Neville Calleja (Malta), Danijela Jonjić (Croatia), Patricia Vella Bonanno (Malta), Natasha Azzopardi Muscat (WHO), Agnese Lazzari (UK), Jon Cylus (UK), Peter Pažitny (Czech Republic), Jana Mrak (Slovenia), Andrea Silenzi (Itália), Walter Ricciardi (Italy), Isabelle Durand-Zaleski (France) and Francesca Ferre (Italy).

\section{Conflict of Interest Statement}

The authors have no conflicts of interest to declare.

\section{Funding Sources}

No funding sources are included in this study.

\section{Author Contributions}

The first author was responsible for all the research and the remaining authors for the review.

\section{References}

1 International Diabetes Federation. Atlas. 8th ed. [Internet]. Brussels: IDF Publishing; 2017. [cited 13/03/2018]. Available from: https:// diabetesatlas.org/IDF_Diabetes_Atlas_8e_ interactive_EN/

2 OECD. Health at a glance 2015: OECD Indicators [Internet]. Paris: OECD Publishing; 2015. [cited 20/03/2018]. Available from: http://apps.who.int/medicinedocs/documents/s22177en/s22177en.pdf

3 OECD. Health at a glance: Europe 2018: state of health in the EU cycle [Internet]. Paris: OECD Publishing; 2018. [cited 2019 Jun 02]. https://doi.org/10.1787/health_glance_eur2018-en.

4 Jacob S, Marx N. [Pharmacotherapy of diabetes mellitus type 2. From the glucocentric tradition towards cardiovascular risk management]. Internist (Berl). 2006 Apr;47(4):434-40.

5 OECD. Health at a glance: Europe 2018: state of health in the EU cycle [Internet]. Paris: OECD Publishing; 2018. [cited 08/02/2020]. Available from: https://ec.europa.eu/health/ sites/health/files/state/docs/2018_healthatglance_rep_en.pdf

6 Institute for Health Metrics and Evaluation. Findings from the Global Burden of Disease Study 2017 [Internet]. Seattle, WA: IHME; 2018. [cited 22/05/2018]. Available from: http:// www.healthdata.org/sites/default/files/files/ policy_report/2019/GBD_2017_Booket.pdf
7 World Health Organization. Data and statistics: diabetes [Internet]. Copenhagen: WHO Publications; 2019. [cited 01/03/2019]. Available from: http://www.euro.who.int/en/ health-topics/noncommunicablediseases/diabetes/data-and-statistics

8 Allemann SS, van Mil JW, Botermann L, Berger K, Griese N, Hersberger KE. Pharmaceutical care: the PCNE definition 2013. Int J Clin Pharm. 2014 Jun;36(3):544-55.

9 Pharmaceutical Group of European Union. PGEU Annual Report 2010 [Internet]. Brussels: PGEU Publishing; 2010. [cited 25/05/2020]. Available from: https://pgeuannual-report.eu/

10 Pharmaceutical Group of European Union. PGEU Annual Report 2017. [Internet]. Brussels: PGEU Publishing; 2017. [cited 13/08/2018]. Available from: https://www. pgeu.eu/wp-content/uploads/2019/04/ PGEU-AR-2017-WEB.pdf

11 British Diabetic Association. Diabetes care and research in Europe: the Saint Vincent declaration. Diabet Med. 1990 May;7(4):360.

12 International Diabetes Federation. Diabetes and cardiovascular disease. [Internet]. Brussels: IDF Publications; 2016. [cited 11/05/2019]. Available from: https://idf.org/ our-activities/care-prevention/cardiovasculardisease/cvd-report.html
13 Al-Lawati JA. Al-Lawati J. Diabetes mellitus: a local and global public health emergency. Oman Med J. 2017 May;32(3):177-9.

14 International Diabetes Federation. A guide to National Diabetes Programs. [Internet]. Brussels: IDF Publications; 2010. [cited 13/03/2019]. Available from: https://d-net. idf.org/en/library/167-a-guide-to-nationaldiabetesprogrammes.html

15 International Diabetes Federation. Integrating diabetes evidence into practise: challenges and opportunities to bridge the gaps. [Internet]. Brussels: IDF Publications; 2017. [cited 13/03/2018]. Available from: https://www.idf. org/our-activities/advocacy-awareness/resources-and-tools/140integrating-diabetesevidence-into-practice.html

16 European Union. EU diabetes epidemic European Parliament resolution of 14 March 2012 on addressing the $\mathrm{EU}$ diabetes epidemic (2011/2911(RSP). [Internet]. Luxembourg: Publications Office of the European Union; 2012. [cited 13/03/2018]. Available from: https://publications.europa.eu/en/publication-detail/-/publication/b818a910-1234- 11e3-8d1c-01aa75ed71al

17 World Health Organization. Action Plan for Prevention and Control of Noncommunicable Diseases 2012-2016. Copenhagen: WHO Regional Office for Europe; 2012. [cited 13/03/2018]. Available from: http://www.euro.who.int/_data/assets/pdf_file/0019/170155/e96638.pdf?ua =1 
18 Ewen M, Zweekhorst M, Regeer B, Laing R. Baseline assessment of WHO's target for both availability and affordability of essential medicines to treat non-communicable diseases. PLoS One. 2017 Feb;12(2):e0171284.

19 Soares M. PharmaDiaB: improved quality in diabetes care: the pharmacist in the St. Vincent team: protocol and guidelines [Internet] Copenhagen: WHO Regional Office for Europe; 2001.[ [cited 2019 Jan 03]], Available from https://apps.who.int/iris/handle/10665/107409

20 International Pharmaceutical Federation. FIP/WHO guidelines on good pharmacy practice: standards for quality of pharmacy services [Internet]. Brussels: FIP Publications; 2011. [cited 14/05/2019]. Available from: https://www.fip.org/file/1476

21 Pizarro ÂM, Martins MR, Simões JA. Expanding primary care to pharmaceutical patient care in type 2 diabetes mellitus through the European Union's community pharmacies, between 2008 and 2018: a systematic review. Port J Public Health. 2019;37(2-3):10018.

22 Cipolle R, Strand L, Morley P. Pharmaceutical care practice: the clinician's guide. 2nd ed. New York (NY): McGraw-Hill; 2004.[Internet].

23 Sánchez AM. Teaching patient-centered care to pharmacy students. Int J Clin Pharm. 2011 Feb;33(1):55-7.

24 Cavaco A, Roter D. Pharmaceutical consultations in community pharmacies: utility of the Roter Interaction Analysis System to study pharmacist-patient communication. Int J Pharm Pract. 2010 Jun;18(3):141-8.

25 Babar ZU, Kousar R, Murtaza G, Azhar S, Khan SA, Curley L. Randomized controlled trials covering pharmaceutical care and medicines management: A systematic review of literature. Res Social Adm Pharm. 2018 Jun;14(6):521-39.

26 Moullin JC, Sabater-Hernández D, Fernandez-Llimos F, Benrimoj SI. Defining professional pharmacy services in community pharmacy. Res Social Adm Pharm. 2013 NovDec;9(6):989-95.

27 Köberlein-Neu J, Mennemann H, Hamacher S, Waltering I, Jaehde U, Schaffert C, et al. Interprofessional medication management in patients with multiple morbidities. Dtsch Arztebl Int. 2016 Nov;113(44):741-8.

28 Twigg MJ, Desborourgh JA, Bhattacharya D, Wright DJ. An audit of prescribing for type II diabetes in primary care: optimising the role of the $\mathrm{CPH}$ in the primary healthcare team. Prim Health Care Res Dev. 2013;14(3):315-9.

29 Diabetes UK. Meet your healthcare team [Internet]London: Diabetes UK; 2021.[], Available at https://www.diabetes.org.uk/guideto-diabetes/managing-your-diabetes/interactions-with-healthcare-professionals
30 Dowell A, Stubbe M, Macdonald L, Tester R, Gray L, Vernall S, et al. Vernall Set al. A longitudinal study of interactions between health professionals and people with newly diagnosed diabetes. Ann Fam Med. 2018 Jan;16(1):37-44.

31 Nolan CJ, Damm P, Prentki M. Type 2 diabetes across generations: from pathophysiology to prevention and management. Lancet. 2011 Jul;378(9786):169-81.

32 Ahlqvist E, Storm P, Käräjämäki A, Martinell M, Dorkhan M, Carlsson A, et al. Novel subgroups of adult-onset diabetes and their association with outcomes: a data-driven cluster analysis of six variables. Lancet Diabetes Endocrinol. 2018 May;6(5):361-9.

33 Wilkinson IB, Raine T, Wiles K, Goodhart A, Hall C, O'Neill H. Oxford handbook of clinical medicine. 10th ed. Oxford: Oxford University Press; 2017. https://doi.org/10.1093/ med/9780199689903.001.0001.

34 Medical Advisory Secretariat. Behavioral interventions for type 2 diabetes: an evidencebased analysis. Ont Health Technol Assess Ser. 2009;9(21):1-45.

35 Smits KP, Sidorenkov G, Bilo HJ, Bouma M, Navis GJ, Denig P. Process quality indicators for chronic kidney disease risk management: a systematic literature review. Int J Clin Pract. 2016 Oct;70(10):861-9.

36 Hepler CD, Strand LM. Opportunities and responsibilities in pharmaceutical care. Am J Hosp Pharm. 1990 Mar;47(3):533-43.

37 Hijmans H, Raab C. Ethical dimensions of the GDPR. In: Cole M, Boehm F, editors. Commentary on the General Data Protection Regulation. Cheltenham: Edward Elgar; 2018.

38 Unhurian L. Implementation of standards of good pharmacy practice in the world: a review. Asian J Pharm. 2018;12 Suppl 1:S42-6.

39 World Health Organization. Improving the quality of health services: tools and resources. Geneva: WHO; 2018. [cited 08/10/2020]. Available from: https://www.who.int/servicedeliverysafety/improving-quality-health-services/en/

40 Garattini L, Padula A, Freemantle N. Do European pharmacists really have to trespass on medicine? Eur J Health Econ. 2021 Feb;22(1):1-4.

41 Scheepers H. Pharmacy preparations: European quality standards and regulation. Maastricht: Universitaire Pers Maastricht; 2017. $\mathrm{PhD}$ Thesis. [cited 11/10/2019]. Available from: https://cris.maastrichtuniversity.nl/en/ publications/pharmacy-preparations-european-quality-standards-and-regulation

42 Patcheva J, Mladenovska K, PetrusevskaTozi L. Legal status of pharmacy practice in the European Union and the Republic of Macedonia. Maced Pharm Bull. 2012;58(12):53-64.

43 Švarcaitė J. Overview of Community Pharmacy Services in Europe. Brussels: PGEU Publishing; 2016.[ [cited 2019 Dec 12]], Available from https://www.oecd.org/els/health-systems/Item-2b-Overview-Community-Pharmacy-Services-Svarcaite\%20.pdf
44 International Pharmaceutical Federation. Beating non-communicable diseases in the community: the contribution of pharmacists. The Hague: International Pharmaceutical Federation; 2019. [cited 12/10/2020]. Available from: https://www.fip.org/file/4694

45 International Pharmaceutical Federation. FIP statement of policy: the roles of pharmacists in non-communicable diseases. The Hague: International Pharmaceutical Federation; 2019. [cited 23/04/2020]. Available from: https://www.fip.org/file/4338

46 Mackenbach J, McKee M. Successes and failures of health policy in Europe: four decades of divergent trends and converging challenges. Berkshire: WHO Publications; 2013. https://doi.org/10.1093/eurpub/ckt125.002

47 Mil J, Schulz M. Review of pharmaceutical care in community pharmacy in Europe. Harv Law Rev. 2006;7(1):155-68.

48 Legido-Quigley H, Panteli D, Car J, McKee M, Busse R. Clinical guidelines for chronic conditions in the European Union. Copenhagen: WHO Regional Office for Europe; 2013. Available from: https://www.euro.who.int/ en/publications/abstracts/clinical-guidelines-for-chronic-conditions-in-the-european-union-2013

49 Schneider CR, Everett AW, Geelhoed E, Kendall PA, Murray K, Garnett P, et al. Provision of primary care to patients with chronic cough in the community pharmacy setting. Ann Pharmacother. 2011 Mar;45(3):402-8.

50 Pharmaceutical Group of European Union. Pharmacy 2030: a vision for community pharmacy in Europe. Brussels: PGEU Publishing; 2019. [cited 08/10/2020]. Available from: https://www.pgeu.eu/wp-content/uploads/2019/03/Pharmacy-2030_-A-Visionfor-Community-Pharmacy-in-Europe.pdf

51 Florentinus SR, van Hulten R, Kloth ME, Heerdink ER, Griens AM, Leufkens HG, et al.; Netherlands Institute for Health Services Research. The effect of pharmacotherapy audit meetings on early new drug prescribing by general practitioners. Ann Pharmacother. 2007 Feb;41(2):319-24.

52 Higgins JP, Thomas J, Chandler J, Cumpston M, Li T, Page MJ, et al., editors. Cochrane Handbook for Systematic Reviews of Interventions: version 6.1 (updated September 2020). London: Cochrane; 2020., Available from www.training.cochrane.org/handbook

53 Amir-Behghadami M, Janati A. Population, Intervention, Comparison, Outcomes and Study (PICOS) design as a framework to formulate eligibility criteria in systematic reviews. Emerg Med J. 2020 Jun;37(6):387.

54 Fronteira I. Manual de epidemiologia. Coimbra: Almedina; 2018

55 Liberati A, Altman DG, Tetzlaff J, Mulrow C, Gøtzsche PC, Ioannidis JP, et al. The PRISMA statement for reporting systematic reviews and meta-analyses of studies that evaluate healthcare interventions: explanation and elaboration. BMJ. 2009 Jul;339 jul21 1:b2700. 
56 Sterne JA, Hernán MA, Reeves BC, Savović J, Berkman ND, Viswanathan M, et al. ROBINS-I: a tool for assessing risk of bias in nonrandomised studies of interventions. BMJ. 2016 Oct; $355: i 4919$.

57 Boparai JK, Singh S, Kathuria P. How to design and validate a questionnaire: a guide. Curr Clin Pharmacol. 2018;13(4):210-5.

58 International Pharmaceutical Federation. FIP website. Brussels: FIP; 2021. [cited 21/07/2020]. Available from: https://www.fip. org/member-organisations

59 Pharmaceutical Group of European Union. PGEU website. Brussels: PGEU; 2021. [cited 21/07/2020]. Available from: https://www. pgeu.eu/members

60 Ferrer P, Ballarín E, Sabaté M, Petri H, Goh KL, Solari P, et al. Drug consumption databases in Europe. Barcelona: PROTECT Project; 2011.[], Available from https://protectbenefitrisk.eu/documents/DUinventory_2011_6_WORD97-2003.pdf

61 World Health Organization. Noncommunicable diseases country profiles 2014. Geneva: World Health Organization; 2014.

62 Andreassen LM, Kjome RL, Sølvik UØ, Houghton J, Desborough JA. The potential for deprescribing in care home residents with Type 2 diabetes. Int J Clin Pharm. 2016 Aug;38(4):977-84.

63 Ayadurai S, Hattingh HL, Tee LB, Md Said SN. A Narrative review of diabetes intervention studies to explore diabetes care opportunities for pharmacists. J Diabetes Res. 2016;2016:5897452.

64 Ayorinde AA, Porteous T, Sharma P. Screening for major diseases in community pharmacies: a systematic review. Int J Pharm Pract. 2013 Dec;21(6):349-61.

65 Gmeiner T, Horvat N, Kos M, Obreza A, Vovk T, Grabnar I, et al. Curriculum Mapping of the Master's Program in Pharmacy in Slovenia with the PHAR-QA Competency Framework. Pharmacy (Basel). 2017 May;5(2):24.

66 Langer T, Spreitzer H, Ditfurth T, Stemer G, Atkinson J. Pharmacy practice and education in Austria. Pharmacy (Basel). 2018 Jun;6(3):55.

67 Lemmens-Gruber R, Hahnenkamp C, Gössmann U, Harreiter J, Kamyar MR, Johnson $\mathrm{BJ}$, et al. Evaluation of educational needs in patients with diabetes mellitus in respect of medication use in Austria. Int J Clin Pharm. 2012 Jun;34(3):490-500.
68 Lowrie R, Mair FS, Greenlaw N, Forsyth P, Jhund PS, McConnachie A, et al.; Heart Failure Optimal Outcomes from Pharmacy Study (HOOPS) Investigators. Pharmacist intervention in primary care to improve outcomes in patients with left ventricular systolic dysfunction. Eur Heart J. 2012 Feb;33(3):314-24.

69 Martins S, Costa F, Carmona M. Implementação de cuidados farmacêuticos em Portugal: seis anos depois. Rev Port Farmacoter. 2013;5:255-63.

70 Martins SF, van Mil JW, da Costa FA. The organizational framework of community pharmacies in Europe. Int J Clin Pharm. 2015 Oct:37(5):896-905.

71 Morton K, Pattison H, Langley C, Powell R. A qualitative study of English community pharmacists' experiences of providing lifestyle advice to patients with cardiovascular disease. Res Social Adm Pharm. 2015 JanFeb;11(1):e17-29.

72 Nachtigal P, Šimůnek T, Atkinson J. Pharmacy Practice and education in the Czech Republic. Pharmacy (Basel). 2017 Oct;5(4):54.

73 Taylor J, Krska J, Mackridge A. A community pharmacy-based cardiovascular screening service: views of service users and the public. Int J Pharm Pract. 2012 Oct;20(5):277-84.

74 Twigg MJ, Wright DJ, Thornley T, Haynes L. Community pharmacy type 2 diabetes risk assessment: demographics and risk results. Int J Pharm Pract. 2015 Feb;23(1):80-2.

75 van Geffen EC, Philbert D, van Boheemen C, van Dijk L, Bos MB, Bouvy ML. Patients' satisfaction with information and experiences with counseling on cardiovascular medication received at the pharmacy. Patient Educ Couns. 2011 Jun;83(3):303-9.

76 Wirth F, Tabone F, Azzopardi LM, Gauci M, Zarb-Adami M, Serracino-Inglott A. Consumer perception of the community pharmacist and community pharmacy services in Malta.JPharmHealthServRes.2010;1(4):18994.

77 Croatian Chamber of Pharmacists. Pharmacy in Croatia. Zagreb: Croatian Chamber of Pharmacists; 2019. [Internet]. [cited 12/03/2019]. Available from: https://www. hljk.hr/pharmacy-in-croatia-a42

78 Regulation (EU) 2016/679 of the European Parliament and of the Council of 27 April 2016. Brussels: Publications Office of the European Union; 2016. [cited 15/02/2021] Available from: https://eur-lex.europa.eu/legal-content/EN/TXT/PDF/?uri=CELEX:320 16R0679\&from $=\mathrm{EN}$
79 Resolution CM/Res (2020)3 on the implementation of pharmaceutical care for the benefit of patients and health services. Strasbourg: Council of Europe; 2020. [cited 12/10/2020]. Available from: https://rm.coe. int/09000016809cdf26]

80 OECD. Health at a Glance 2020: OECD Indicators. Paris: OECD Publishing; 2020. [cited 02/02/2021]. Available from: https://www. oecd-ilibrary.org/docserver/82129230-en.pd f?expires $=1614686339 \&$ id $=i d \&$ accname $=$ gue st\&checksum $=7921 \mathrm{D} 1 \mathrm{FF} 2 \mathrm{BF} 3 \mathrm{D} 88 \mathrm{~B} 3 \mathrm{~F} 58 \mathrm{AA}$ F0FAE1F72B]

81 Paulweber B, Valensi P, Lindström J, Lalic NM, Greaves CJ, McKee M, et al. A European evidence-based guideline for the prevention of type 2 diabetes. Horm Metab Res. 2010 Apr;42(S 01 Suppl 1):S3-36.

82 Costa F, Mil J, Risco A. The pharmacist guide to implementing pharmaceutical care. Cham: Springer; 2019.

83 Sepp K. Critical pathways: the role of pharmacies in Estonia today and tomorrow. Estonia: Eestiapteek; 2015. [cited 14/07/2020; available from: http://www.efs.ee/baltpharm2015/the role_of_pharmacies_in_estonia_today_and_ tomorrow.pdf].

84 Pharmaceutical Group of European Union. PGEU Annual Report 2014. Promoting efficiency, improving lives. Brussels: PGEU Publications; 2014. [cited 23/01/2019]. Available from: https://www.pgeu.eu/en/library/258: annual-report-2014.html

85 Economics DA. Department of Health. Remuneration and regulation community pharmacy: a literature review. Canberra: Deloitte Publishing; 2016. [cited 2018 Dec 12], Available from https://www1.health.gov.au/internet/main/publishing.nsf/Content/4E0B6EEE 19F56A40CA2581470016D688/\$File/deloitte-community-pharmacy-literature-review-2016.pdf

86 Consoli A, Di Fulvio P. [Cardiovascular risk reduction in the management of diabetic patients: what has changed since the '90s in the clinical approach?]. G Ital Cardiol (Rome). 2014 Dec;15(12 Suppl 2):21S-6S.

87 Rijcken C. The jungle of health apps. In: Rijcken $\mathrm{C}$, editor. Pharmaceutical care in digital revolution: insights Towards Circular Innovation. Frisco: Elsevier Science \& Technology; 2019. pp. 95-105. 